\title{
Post weld treatment of dissimilar friction stir welded-aluminum alloys 5754-6082
}

\author{
E. A. El-Danaf \& M. M. El Rayes \\ Mechanical Engineering Department, College of Engineering, \\ King Saud University, Saudi Arabia
}

\begin{abstract}
5754-6082 aluminum alloys are friction stir welded at $1070 \mathrm{rpm} / 140 \mathrm{~mm} / \mathrm{min}$, and the welded joint was observed to be defect free. The friction stir welded plate was, further, rolled at an intermediate temperature of $250^{\circ} \mathrm{C}$ in the direction of the weld line. The effect of post weld treatment by isothermal heating or shot peening or combination of both, on the mechanical properties, was investigated. The welded section was characterized by optical microscopy, hardness mapping and X-ray diffraction, on the transverse section. Tensile samples were wire-cut having the weld nugget in the middle of the gauge length. Enhancement of yield, tensile strength and percentage of elongation to failure was noted, for specific post weld treatment conditions.

Keywords: friction stir welding, aluminium alloys, post weld treatment, shot peening.
\end{abstract}

\section{Introduction}

Friction stir welding (FSW) is a relatively new solid state joining process. It requires no local melting in order to join pieces together. This joining technique is energy efficient, environment friendly, and versatile. The basic concept of FSW is remarkably simple. A non-consumable rotating tool with a specially designed pin and shoulder is inserted into the abutting edges of sheets or plates to be joined and traversed along the line of joint. The tool serves two primary functions: (a) heating of the work piece, and (b) movement of material to produce the joint. The heating is accomplished by friction between the tool and the work piece and plastic deformation of the work piece. During FSW process, the material undergoes intense plastic deformation at an elevated temperature, 
resulting in the generation of fine and equiaxed recrystallized grains [1]. The fine microstructure in friction stir welds produces good mechanical properties [1-4]. Recently friction stir processing (FSP) was developed by Mishra and Mahoney [5] as a generic tool for microstructural modification based on the basic principles of FSW. Friction stir processing (FSP) is a new solid state technique which uses the principles of friction stir welding to process materials in a variety of other ways besides joining them. FSP has developed into a broad field covering microforming, casting modification, powder processing, and channeling. Among different severe plastic deformation techniques, friction stir processing (FSP) [6] and equal channel angular pressing (ECAP) [7] have been the main focus of researchers.

As the need for materials that possess such properties of strength, lightweight, high corrosion resistance, high thermal and electrical conductivity, hot and warm formability, has steadily been increasing, there has also been a growing interest in aluminum alloys which provide such properties like that found in agehardenable 6082 AA and wrought non-heat treatable 5754 AA. The 6xxx-group of aluminium alloys contains magnesium and silicon as the major alloying elements. Al-Mg-Si alloys have recently been used for automotive body sheet panel for weight saving. These multiphase alloys belong to a group of commercial aluminium alloys, in which relative volume, chemical composition, and morphology of the structural constituents exert a significant influence on their useful properties [8-10]. The $\mathrm{Al}-\mathrm{Mg}-\mathrm{Si}$ alloys can be strengthened by the precipitation of the metastable precursors to the equilibrium $\beta(\mathrm{Mg} 2 \mathrm{Si})$ phase. An understanding of these precipitation mechanisms during artificial aging is critical for achieving optimal properties. A number of studies on the aging aluminium of $\mathrm{Al}-\mathrm{Mg}-\mathrm{Si}$ alloys are available. Miao and Laughlin [11-13] suggested the following precipitation sequence for the $6022 \mathrm{Al}-\mathrm{Mg}-\mathrm{Si}$ alloy:

$\alpha$ (sss) $\rightarrow$ GP zones $\rightarrow \beta$ " needles $\rightarrow \beta$ ' rods + lath-like particles $\rightarrow \beta+\mathrm{Si}$ (various morphologies)

where $\alpha$ (sss) is the supersaturated solid solution and GP zones are spherical clusters having an unknown structure. The exact composition of the alloy and the casting condition will directly influence the volume fraction of intermetallic phases present $[12,14] .5754 \mathrm{AA}$ is a non-heat treatable aluminium alloy that has excellent corrosion resistance and weldability combined with good strength and formability. It is the material of choice for superplastic automotive and aerospace aluminium panels.

The current work focuses on the friction stir welding of dissimilar aluminium alloys; heat treatable 6082 AA with non-heat treatable 5754. The work investigates different possible post weld treatments namely hot rolling of the weldments, heat treatment and shot peening and combination of the aforementioned post weld treatment techniques to improve the integrity of the welded section as would be reflected in the mechanical properties. 


\section{Experimental procedure}

Hot rolled plates $6 \mathrm{~mm}$ thick, $100 \mathrm{~mm}$ wide and $120 \mathrm{~mm}$ long of 6082 AA with a nominal composition in wt. \% 1.2 Si, 0.75 Mg, 0.79 Mn and 97.01 Al, and 5754 AA with nominal composition in wt $\% 3 \mathrm{Mg}, 0.4 \mathrm{Mn}, 0.3 \mathrm{Si}$, and $96 \mathrm{Al}$,were used. FSW runs were conducted perpendicular to the rolling direction using a rotational speed of $1070 \mathrm{rpm}$ with a feed rate of $140 \mathrm{~mm} / \mathrm{min}$. The tool was manufactured from Mo-W tool steel with a flat shoulder of $15 \mathrm{~mm}$ diameter, and a concentric square pin with an edge length of $6 \mathrm{~mm}$, and $5 \mathrm{~mm}$ long as shown in Fig. 1(a). Test set-up is shown schematically in Fig. 1(b). Part of the welded piece was further hot rolled in the weld direction at a temperature of $250^{\circ} \mathrm{C}$, with a rolling reduction of $10 \%$. Tensile samples were wire cut perpendicular to the weld direction, with SZ being centered within the gage length. Fig. 1(c) shows how the tensile samples were extracted, by wire cutting, from the weld piece. Tensile samples extracted from the welded and rolled condition was further subjected to isothermal annealing at $180^{\circ} \mathrm{C}$ for three different time periods of 6 , 12 and $24 \mathrm{hrs}$. The tensile samples was also subjected to two different shot peening surface treatment conditions on the gage section, where the stand-ofdistance was kept constant at $25 \mathrm{~cm}$ (constant pressure) for two time durations of 8 and 12 seconds, to induce mild to severe surface compressive residual stresses. Microhardness measurements were taken on the specimen's transverse cross section using Vickers microhardness testing using $300 \mathrm{~g}$ load and at $0.3 \mathrm{~mm}$ distance between successive indentations. X-ray diffraction was conducted, on the transverse section, at three locations; at the two base metals as well as in the weld nugget. Optical microscopy was conducted on the transverse section for the as welded condition. Tension tests were conducted at room temperature at an initial strain rate of $10^{-3} \mathrm{~s}^{-1}$.

\section{Results and discussions}

Figs 2(a) and (b) represent the microstructure, on the transverse section at the location of the weld nugget, for the as welded condition. The light colour phase belongs to the $6082 \mathrm{AA}$ where the dark colour phase is the $5754 \mathrm{AA}$, as confirmed from microhardness measurement. The softer properties of the 5754 AA makes it easier for the harder 6082 AA to penetrate through. Fig. 2(b) shows a fragmented island of 6082 AA, encompassed by the softer material 5754 AA.

Fig. 3 represent the engineering stress-strain response for the two base metals along with the welded and welded-rolled conditions. The strength flow response for $6082 \mathrm{AA}$ is higher than $5754 \mathrm{AA}$. Rolling the welded joint has resulted in increasing the yield strength from 60 to $70 \mathrm{MPa}$ as well as in an increase in the tensile strength from 80 to $127 \mathrm{MPa}$. Figs 4(a) and (b) represent the hardness profile variation along the transverse section, spanning the two base metals with the weldment located at the center of the profile, for the as welded and welded followed by rolling (welded-rolled) in (a) and welded-rolled compared to the welded-rolled followed by post weld heat treatment (PWHT) at $180^{\circ} \mathrm{C}$ for $12 \mathrm{hrs}$. It is obvious that the improvement in strength gained by rolling and further heat 


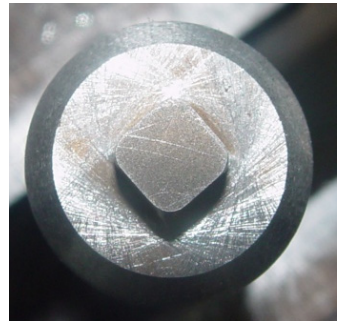

(a)

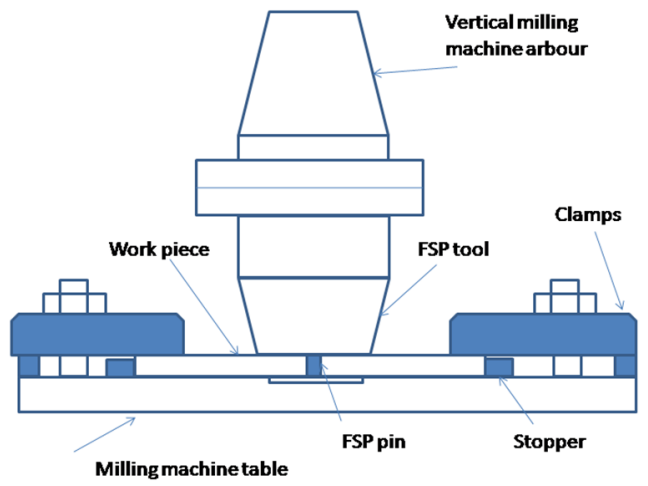

(b)

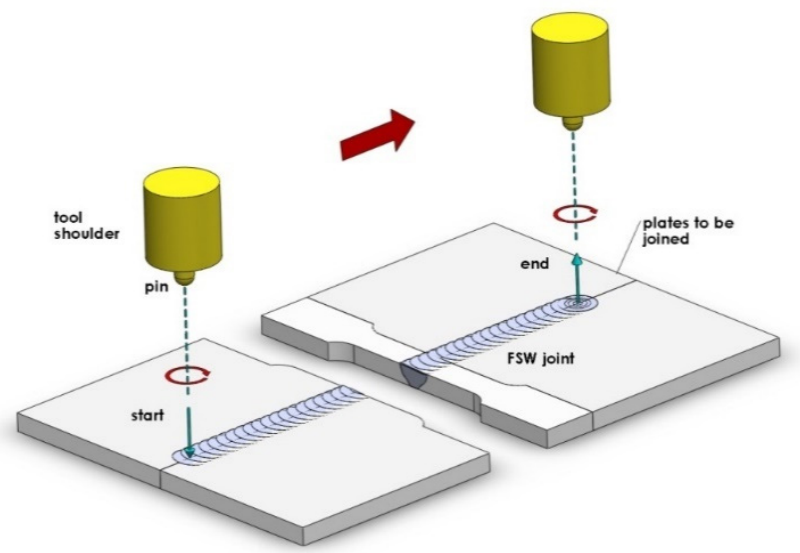

(c)

Figure 1: (a) Image of the tool; (b) schematic of the fixture setup; (c) sketch of the tensile samples were wire cut from the welded plates. 


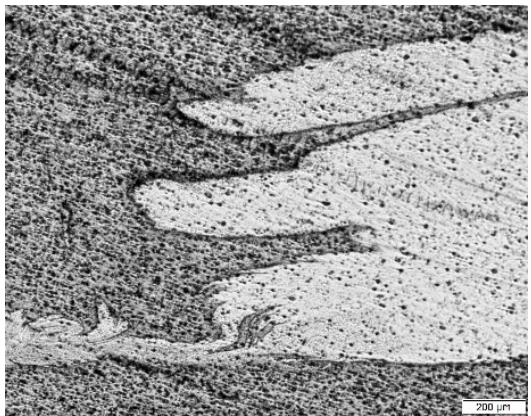

(a)

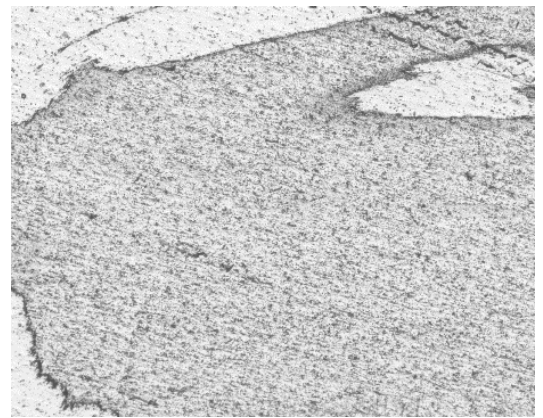

(b)

Figure 2: Microstructure at the interface of the two alloys.

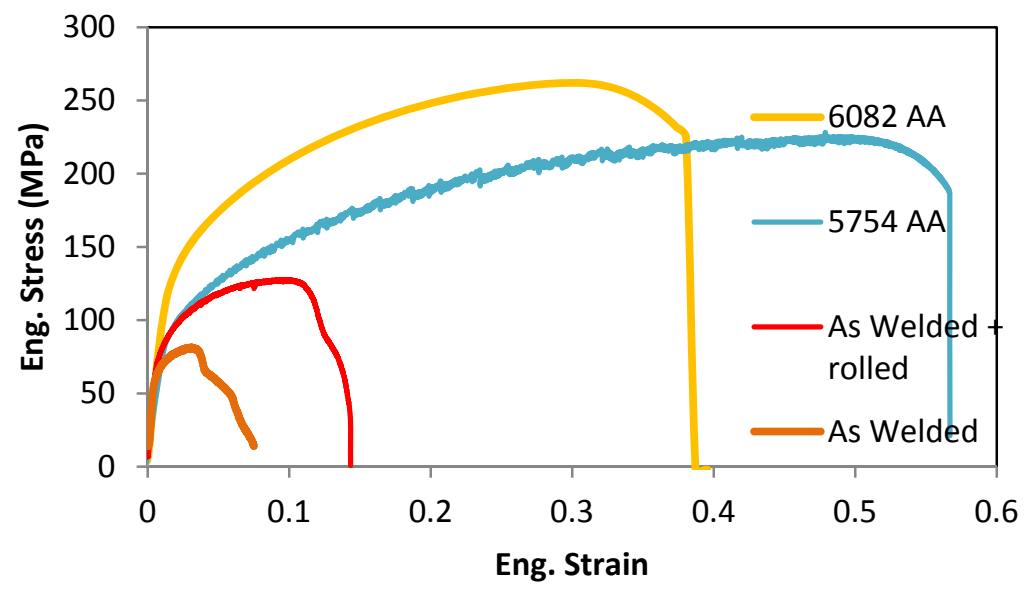

Figure 3: Engineering stress-strain response of the two alloys, as welded and welded + rolled conditions.

treatment. The X-ray diffraction pattern, for the welded-rolled has identified the existence of different intermetallic phases in the weld nugget; namely: $\mathrm{Mg} 2 \mathrm{Si}$, Al-Fe-Si, Al-Si.

Fig. 5 compares the engineering stress-strain response of the welded-rolled condition to the three post weld-rolled heat treatments defined by isothermal annealing to the time durations of 6,12 and $24 \mathrm{hrs}$ at $180^{\circ} \mathrm{C}$. It can be seen that the best result in terms of enhancing the yield, tensile strength and percentage of elongation to failure is achieved with the $12 \mathrm{hrs}$ ' heat treatment. The yield strength has increased from 70 to $120 \mathrm{MPa}$. Tensile strength has also increased 


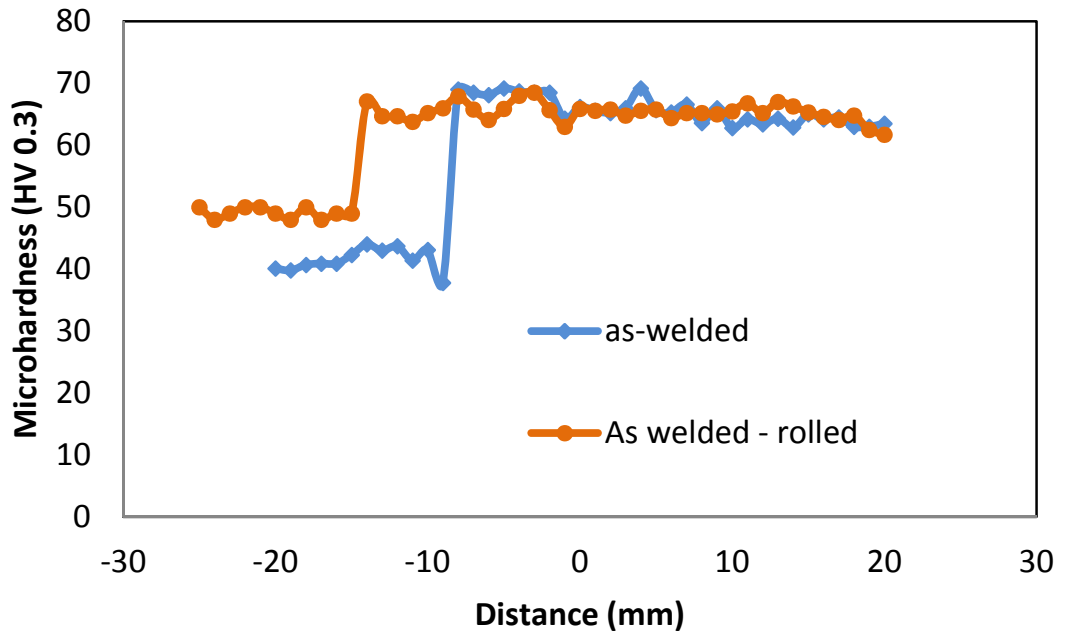

(a)

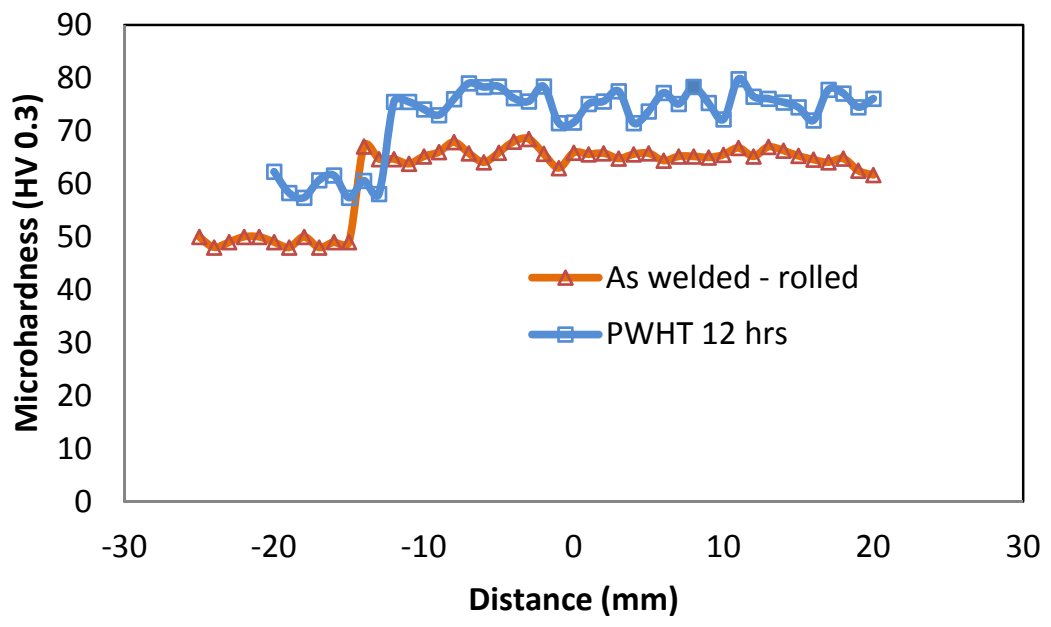

(b)

Figure 4: Hardness variation for the as welded and welded + rolled in (a) and welded + rolled followed by PWHT for $12 \mathrm{hrs}$ in (b).

from 127 to $160 \mathrm{MPa}$. This increase in strength could be due to the possible reprecipitation of the $\beta$ "' precipitates [15]. Fig. 6 compares the engineering stressstrain response of the as welded, welded-rolled and post weld-rolled heat treated for $12 \mathrm{hrs}$. It is clear that the values of yield strength, tensile strength and percent of elongation to failure of the as welded condition were doubled by the post weld rolling and heat treatment. 


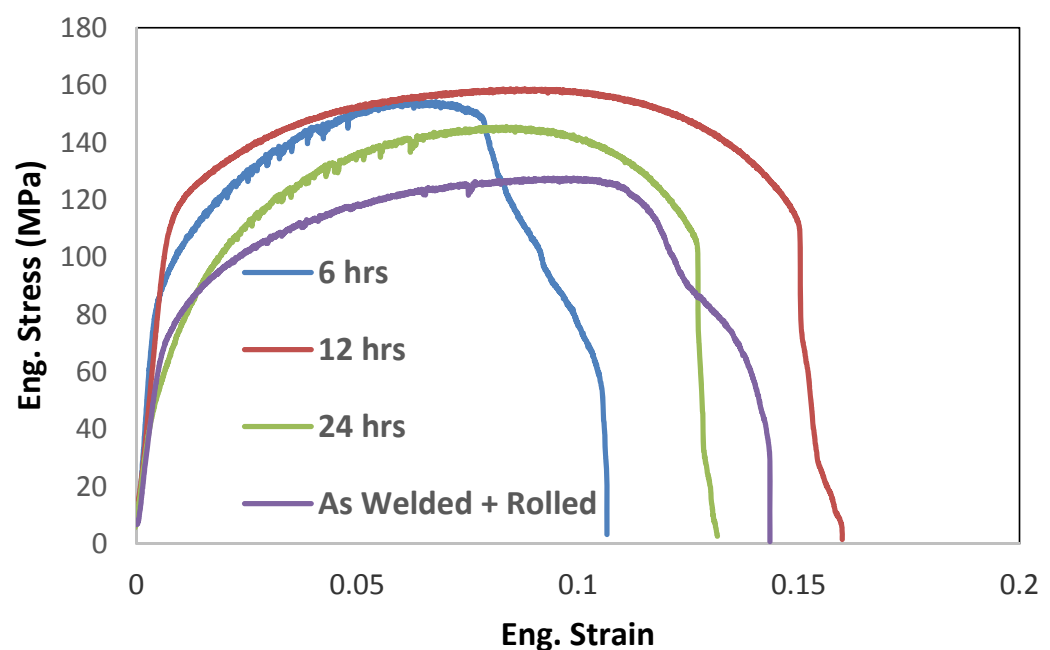

Figure 5: Engineering stress-strain response of welded + rolled condition and post weld - rolled heat treated at $180^{\circ} \mathrm{C}$ for different durations.

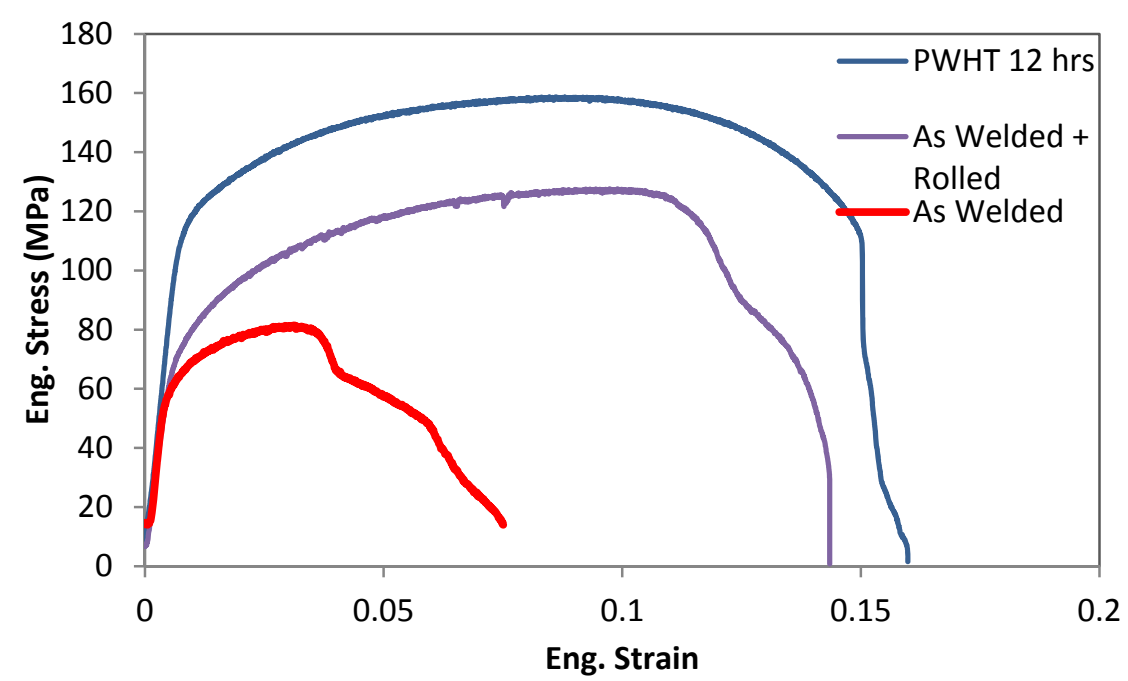

Figure 6: Engineering stress-strain response for three conditions: as welded, welded - rolled and welded - rolled and heat treated at $180^{\circ} \mathrm{C}$ for $12 \mathrm{hrs}$. 
Other post weld treatment investigated was shot peening the gage section to create surface compressive residual stresses. Two durations, of 8 and 12 seconds, were used. Fig. 7 compares the engineering stress-strain response for the two shot peened conditions with the welded-rolled condition. The yield strength increased from 70 to $120 \mathrm{MPa}$, where the tensile strength was almost the same. Also shown is the best response to post weld heat treatment which was for 12 hrs. Fig. 8 shows the engineering stress-strain response for a sample that was subjected to post weld-rolled heat treatment to $12 \mathrm{hrs}$ and further shot peened to 8 seconds along with the sample welded-rolled and further heat treated to $12 \mathrm{hrs}$. The result presented confirms, undoubtedly, that rolling the welded joint and further annealing the joint at $180^{\circ} \mathrm{C}$ for $12 \mathrm{hrs}$ provides the best improvement in the mechanical properties of the weldment. Fig. 9 shows the engineering stressstrain response for the two base metals along with the welded joint subjected to the best post weld treatment, that is the heat treatment at $180^{\circ} \mathrm{C}$ for $12 \mathrm{hrs}$. It is seen that the welded material exhibits a yield strength comparable to the yield strength of the stronger alloy; namely 6082 AA.

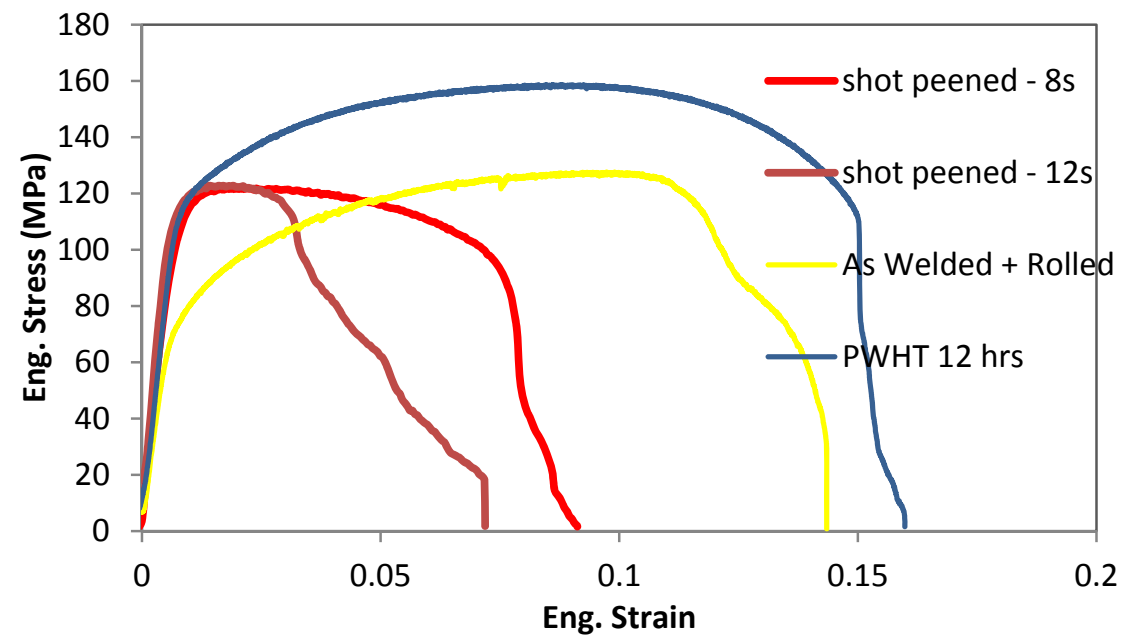

Figure 7: Engineering stress-strain response for the welded - rolled, welded rolled and further shot peened to two durations and welded - rolled and further heat treated at $180^{\circ} \mathrm{C}$ for $12 \mathrm{hrs}$. 


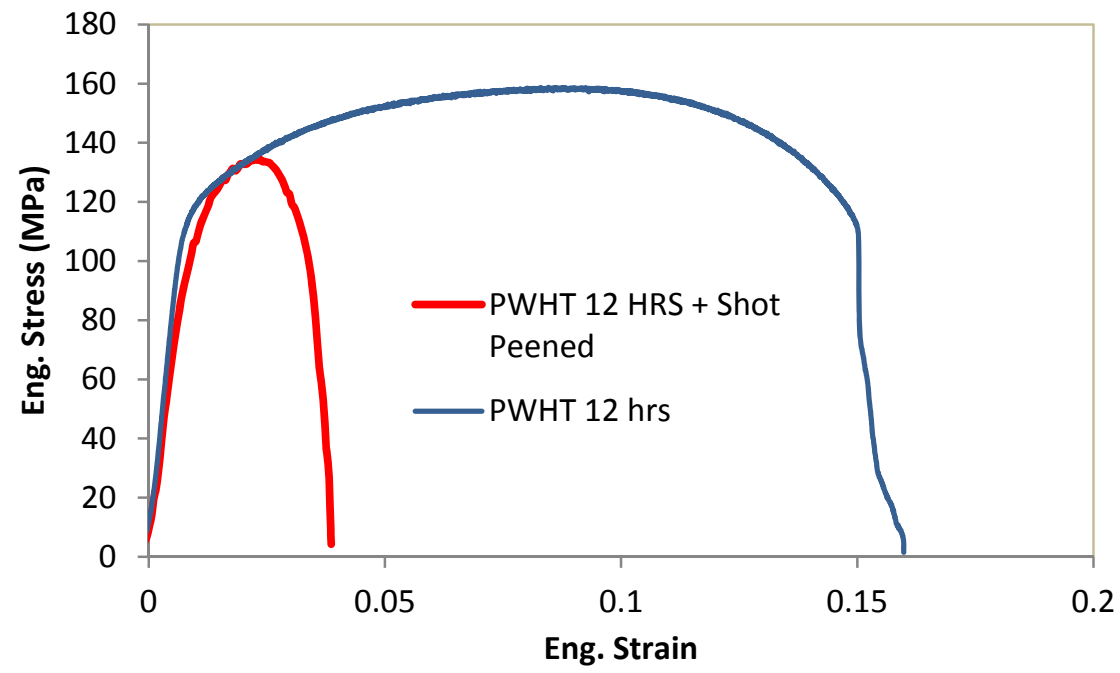

Figure 8: Engineering stress-strain response for the welded - rolled sample subjected to a combination of heat treatment at $180^{\circ} \mathrm{C}$ for $12 \mathrm{hrs}$ and consequently shot peening for 8 seconds.

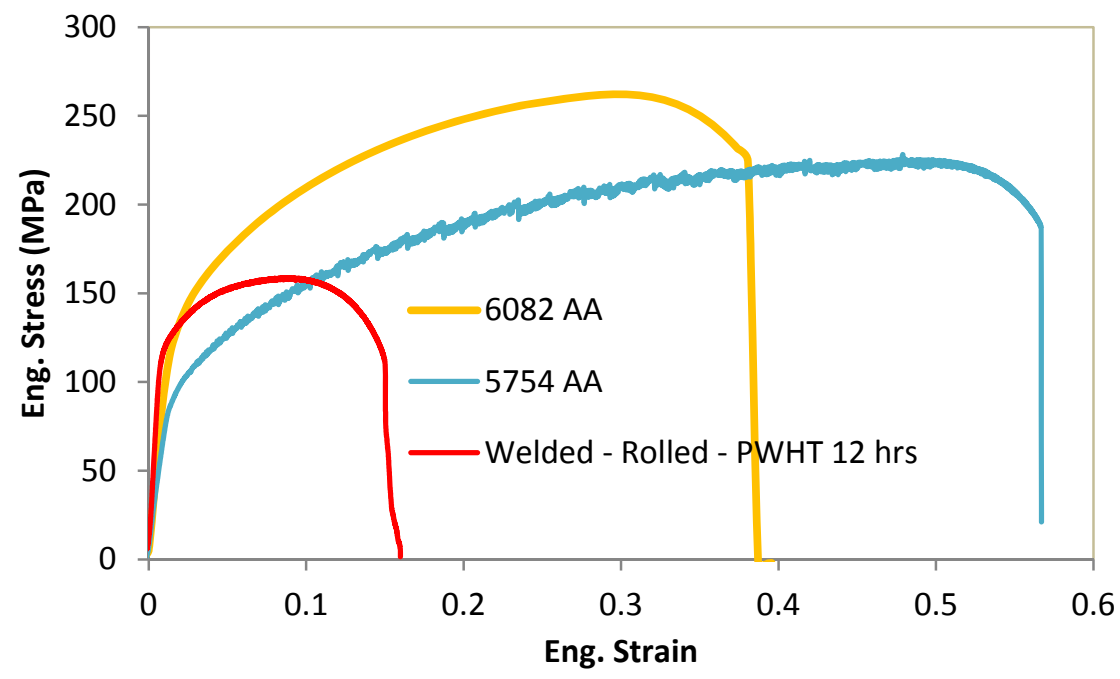

Figure 9: Engineering stress-strain response of the two alloys along with the welded sample subjected to the best post weld practice (heat treatment at $180^{\circ} \mathrm{C}$ for $12 \mathrm{hrs}$ ), 


\section{Conclusions}

Dissimilar stronger 6082 AA to a softer 5754 AA are friction stir welded. The welded material is subjected to post weld rolling, heat treatment and shot peening. The strength is evaluated for all conditions of post weld treatment. The following conclusions can be made:

1. The interface between the two metals is defined by penetration of the stronger alloy into the softer one, which can accommodate fragments of the harder alloy.

2. Post weld rolling and further heat treatment at $180^{\circ} \mathrm{C}$ for $12 \mathrm{hrs}$ results in doubling all mechanical properties in terms of yield, tensile strength and elongation to failure.

3. Subjecting the weldments to the aforementioned treatment results in a yield strength comparable to the yield strength value of the stronger alloy 6082 AA.

\section{Acknowledgement}

The authors would like to thank the Deanship of Scientific research, Research Center, College of Engineering, King Saud University, for supporting this work.

\section{References}

[1] Mishra, R.S., Ma, Z,Y., Friction stir welding and processing. Mater Sci Eng R, 50, pp. 1-78, 2005.

[2] Su, J.Q., Nelson, T.W., Sterling, C.J., Microstructure evolution during FSW/FSP of high strength aluminum alloys. Mat Sci Eng A, 405, pp. 27786, 2005.

[3] Attalla, M.M., Salem, H.G., Friction stir welding parameters: a tool for controlling abnormal grain growth during subsequent heat treatment. Mater Sci Eng A, 391, pp. 51-59, 2005.

[4] Ouyang, J., Yarraparredy, E., Kovacevic, R., Microstructural evolution in the friction stir welded 6061 aluminum alloy (T6-temper condition) to copper. J Mater Process Technol, 172, pp. 110-12, 2006.

[5] Mishra, R.S., Mahoney, M.W., Metal superplasticity enhancement and forming process. US Patent 6, 712, 916; March 302004.

[6] El-Danaf, E.A., El-Rayes, M.M., Soliman, M.S., Friction stir processing: an effective technique to refine grain structure and enhance ductility. Mater Des., 31, pp. 1231-1236, 2010.

[7] El-Danaf, E.A., Mechanical properties, microstructure and texture of single pass equal channel angular pressed 1050, 5083, 6082 and 7010 aluminum alloys with different dies. Mater Des., 32(7), pp. 2838-3853, 2011.

[8] Kuijpers, N.C.W., Kool, W.H., Koenis, P.T.G., Nilsen, K.E., Todd, I.; van der Zwaag, S., Assessment of different techniques for quantification of $\alpha$ - 
$\mathrm{Al}(\mathrm{FeMn}) \mathrm{Si}$ and $\beta$-AlFeSi intermetallics in AA 6xxx alloys. Mater. Charact. 49, pp. 409-420, 2003.

[9] Kuijpers, N.C.W., Vermolen, F.J., Vuik, C., Koenis, P.T.G., Nilsen, K.E., Todd, I., van der Zwaag, S., The dependence of the $\alpha$-AlFeSi to $\beta$ $\mathrm{Al}(\mathrm{FeMn}) \mathrm{Si}$ transformation kinetics in $\mathrm{Al}-\mathrm{Mg}-\mathrm{Si}$ alloys on the alloying elements. Mat. Sci. Eng. A, 394(1-2), pp. 9-19, 2005.

[10] Murayama, M., Hono, K., Saga, M., Kikuchi, M., Atom probe studies on the early stages of precipitation in Al-Mg-Si alloys. Mater. Sci. Eng. A, 250, pp. 127-132, 1998.

[11] Miao, W.F., Laughlin, D.E., Precipitation hardening in aluminum alloy 6022. Scripta Materialia, 40, pp. 873-878, 1999.

[12] Miao, W.F., Laughlin, D.E., A differential scanning calorimetry study of aluminum alloy 6111 with different pre-aging treatments. J. Mater. Sci. Lett., 19, pp. 201-203, 2000.

[13] Miao, W.F., Laughlin, D.E. Effects of $\mathrm{Cu}$ content and pre-aging on precipitation characteristics in aluminum alloy 6022. Metall. Mater. Trans. A, 31, pp. 361-371, 2000.

[14] El-Danaf, E.A., Soliman, M.S., Almajid, A.A., Effect of Solution Heat Treatment on the Hot Workability of Al-Mg-Si Alloy. Materials and Manufacturing Processes, 24, pp. 637-643, 2009.

[15] El-Danaf, E.A., El-Rayes, M.M., Microstructure and mechanical properties of friction stir welded $6082 \mathrm{AA}$ in as welded and post weld heat treated conditions. Mater Des., 46, pp. 561-572, 2013. 